\title{
Metabolism in Penicillium isariiforme on Exposure to Light, with Special Reference to Citric Acid Synthesis
}

\author{
By W. D. J. GRAAFMANS \\ Department of Plant Physiology, University of Amsterdam, The Netherlands
}

(Received 29 October 1973; revised 13 December 1973)

\begin{abstract}
SUMMARY
When exposed to light, cultures of Penicillium isariiforme showed a sharp decrease in citric acid accumulation in the medium compared with parallel cultures in continuous darkness, and a rise in the production of other low molecular weight intracellular intermediates, lipids, nucleic acids and protein. The significance of these phenomena is discussed.
\end{abstract}

\section{INTRODUCTION}

Light can influence metabolism and morphogenesis in a number of fungi. The phototropic responses and effects on vegetative growth, sporulation and carotenoid synthesis are well known and have been reviewed by several authors, e.g. Burnett (I968), Carlile (1970), Smith \& Galbraith (1971).

In Penicillium isariiforme differentiation is governed to a large extent by atmospheric conditions and light. Previously we described the influence of carbon dioxide on sporulation (Graafmans, $1973 a, b$ ). Also, it has been established that the formation of coremia is strictly light-dependent (Carlile, Dickens, Mordue \& Schipper, 1962; Piskorz, 1967). Blue light with a wavelength between 450 and $520 \mathrm{~nm}$ showed the strongest reaction (Bennink, 1972).

Little is known about biochemical changes that occur in this fungus upon light induction. The present paper reports some aspects of metabolism after the transition from dark to light, with particular respect to the synthesis of citric acid.

\section{METHODS}

Unless otherwise mentioned, all procedures were as described previously (Graafmans, I973 a). When not in darkness the fungus was kept in dim blue light (400 to $530 \mathrm{~nm}$ ) with an intensity of $80 \mathrm{erg} / \mathrm{cm}^{2} / \mathrm{s}$ at the culture surface, to get an optimal photomorphogenetic reaction (fluorescent tubes: Philips No. 23; filter: 'Plexiglas' blue No. 627, Röhm and Haas, Darmstadt, Germany). In a separate experiment a 'Plexiglas' red No. 502 filter was used $(>585 \mathrm{~nm}$ ). Light intensities were measured by means of a compensated thermopile type CAI, connected with a microvolt meter type Micrograph BD5 (Kipp en Zn., Delft, Holland).

After incubation with $\left[{ }^{14} \mathrm{C}\right]$ sucrose, the mycelia were thoroughly rinsed to remove contaminating extracellular $\left[{ }^{14} \mathrm{C}\right]$ sucrose. Fractionation of mycelia into chemical components was carried out according to the method of Roberts et al. (1955) with a slight modification in the first step. Lyophilized mycelium was very finely ground with glass powder and extracted for low-molecular-weight intermediates at $2{ }^{\circ} \mathrm{C}$ with $5 \%$ trichloroacetic acid 
(TCA). After centrifuging, this procedure was repeated twice and the three supernatants were combined. Consecutive extraction of the residue, with $75 \%$ ethyl alcohol (EtOH) and $75 \% \mathrm{EtOH} /$ ether at $45{ }^{\circ} \mathrm{C}$, and with $5 \% \mathrm{TCA}$ at $100{ }^{\circ} \mathrm{C}$, provided supernatants that contained mainly lipids, alcohol-soluble protein, hot TCA-extractable carbohydrate and nucleic acids, respectively. The remainder consisted of residual hyphal walls and protein.

The cold TCA-soluble fraction was chromatographed on Dowex-8 anion-exchange resin for separation of organic acids (mainly Krebs-cycle intermediates, aspartic acid and glutamic acid). The first 'neutral fraction' consisting of neutral and basic components was hydrolysed with $2 \mathrm{~N}-\mathrm{HCl}$ at $100{ }^{\circ} \mathrm{C}$ for $5 \mathrm{~h}$. After further deionization on Amberlite mixedbed resin (IR-I 20 H, IRA-400 Ac), radioactive sugars in the eluate were separated by the method of Wessels et al. (1972). Samples were co-chromatographed with glucose, mannose or galactose. Spots were made visible with aniline phthalate and radioactivity was determined by liquid scintillation counting of scraped-off spots.

Chemicals. $\mathrm{Ba}^{14} \mathrm{CO}_{3}$ and $\left[\mathrm{C}^{14}-\mathrm{U}\right]$ sucrose were obtained from The Radiochemical Centre, Amersham, Buckinghamshire, Dowex X8 (200 to 400 mesh) from Fluka A.G., Switzerland, Amberlite resins IR-I $20(\mathrm{H})$ and IRA-400 (Cl) from B.D.H. Chemicals Ltd, and aniline phthalate from Merck.

\section{RESULTS}

\section{Citric acid synthesis after exposure to light}

Cultures of Penicillium isariiforme were grown for five days in darkness and then placed in the light. The citric acid content of the medium and mycelium was determined just before light-induction and on each of the subsequent four days. Cultures in continuous darkness served as controls. In dark-grown cultures the citric acid content in the medium rose, whereas after exposure to light the accumulation was strongly diminished (Fig. I $a$ ). The differences between the citric acid contents in the mycelia were less pronounced. The sucrose uptake and the mycelium dry weights of the cultures used in this experiment are presented in Fig. I $(b),(c)$.

Mycelia were illuminated under blue light because it has the strongest morphogenetic effect (Bennink, 1972). Independently, it was established that, compared with red light of the same intensity (see Methods), blue light also caused the most pronounced decrease in citric acid accumulation. The citric acid content in the media of red-light cultures was I 47 (7) $\mu \mathrm{g} / \mathrm{mg}$ dry wt of mycelium, in blue-light cultures 68 (4) $\mu \mathrm{g}$ and in the dark controls $202(9) \mu \mathrm{g}$. These figures are the averages of determinations in four separate cultures after cultivation for 9 days, of which the last 4 days were in the light; the figures in parentheses are the deviations.

Besides the above-mentioned experiments in which citric acid was colorimetrically determined (Graafmans, 1973a), the rate of synthesis of this compound with time was examined in a pulse-label experiment. The medium of the cultures grown 7 days in darkness or 5 days in the dark and 2 days in the light, was pulsed with $\left[{ }^{14} \mathrm{C}\right]$ sucrose for $\mathrm{I}, 3$ or $6 \mathrm{~h}$. Radioactive citric acid and other metabolites in a TCA-soluble extract of the mycelium and in the medium were then determined after chromatography on Dowex-8 anion-exchange resin. It was apparent that excretion of citric acid into the medium was more intense in dark-grown cultures than in light-exposed ones (Table I). As for the other compounds, strong differences were found in the fraction consisting of neutral and basic metabolites. Here radioactivity increased more in the fractions from the light-exposed mycelia than from the dark-grown controls. 

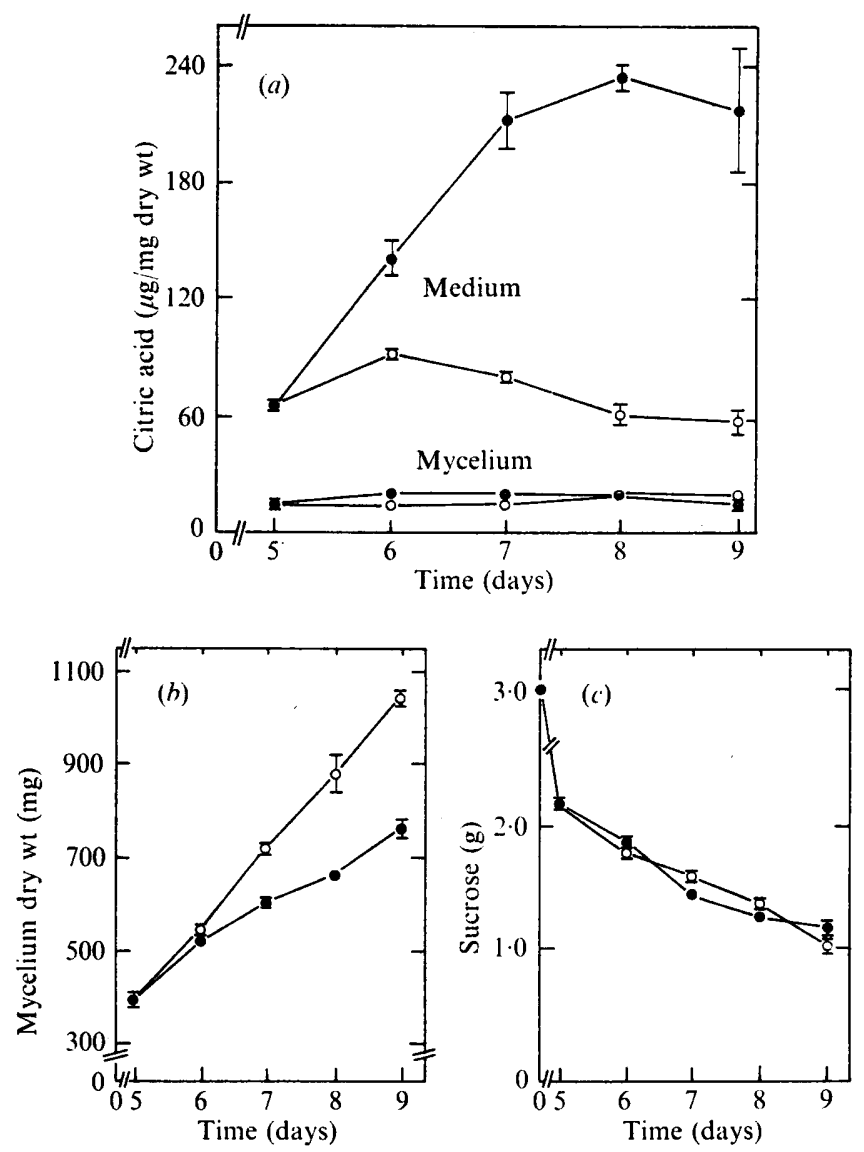

Fig. I. (a) Citric acid content in medium and mycelium of $P$. isariiforme. Citric acid content in medium (two upper curves) expressed in $\mu \mathrm{g}$ excreted in medium $/ \mathrm{mg}$ dry wt mycelium. Citric acid content in mycelium (two lower curves) expressed in $\mu \mathrm{g} / \mathrm{mg}$ dry wt mycelium. (b) Dry weight of mycelium in the same experiment. (c) Sucrose content in the culture media in the same experiment. 0 , Illuminated cultures; $\bullet$, dark-grown cultures. Values are the averages of determinations in two separate cultures, harvested on the days indicated. The range is indicated, unless too small to do so.

\section{Fractionation of ${ }^{14} \mathrm{C}$-labelled mycelium and medium}

We could not find distinct differences in sucrose uptake between cultures exposed to light and dark-grown cultures, although the mycelium dry weights of the illuminated mycelia were always higher than those of the dark controls (cf. Fig. I $b, c$ ). Therefore, it was of interest to establish the distribution of ${ }^{14} \mathrm{C}$-labelled cell components in the two culture types.

Labelling with $\left[{ }^{14} \mathrm{C}\right]$ sucrose from the moment of exposure to light was performed in a culture grown for 5 days in darkness. Distribution of radioactivity after cultivation for another 4 days was compared with a control culture labelled for the same period. All fractions of the illuminated mycelium contained more radioactivity compared with the dark control (Table 2). This was especially true for the cold TCA-soluble fraction. After hydrolysis, pronounced differences were also found in glucose, the only detectable radioactive sugar. 
Table I. Distribution of ${ }^{14} C$ in a TCA-soluble fraction from light-exposed and darkgrown cultures of $P$. isariiforme after pulse-labelling with $\left[{ }^{14} \mathrm{C}\right]$ sucrose*

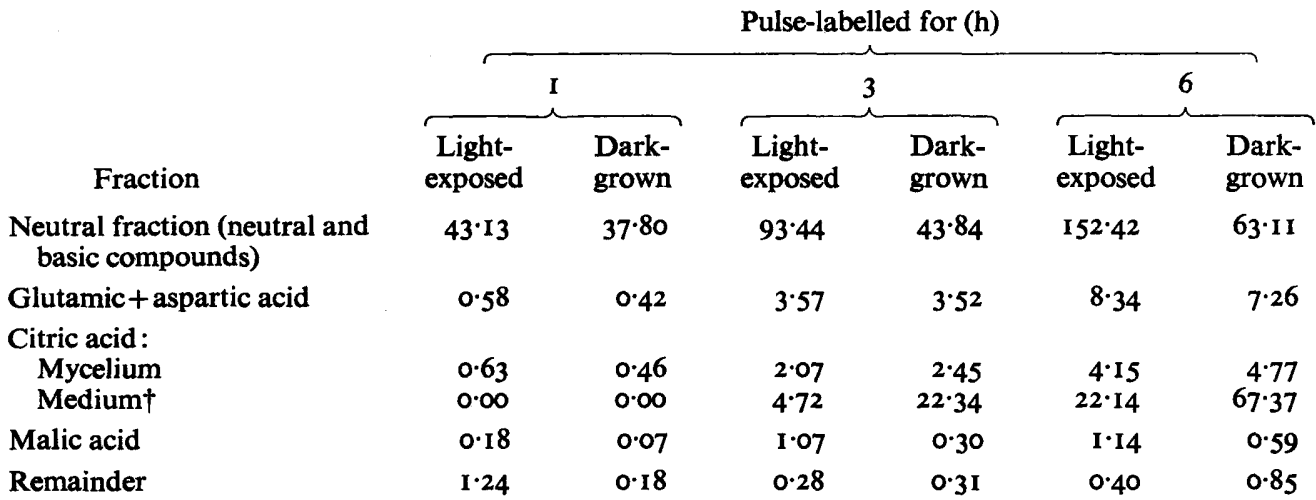

* Radioactivity is expressed as d.p.m./mg dry wt mycelium. $\left[{ }^{14} \mathrm{C}\right]$ sucrose: $9.7 \times 10^{5}$ d.p.m./incubation.

$\dagger$ Radioactivity is expressed as d.p.m. excreted in medium/mg dry wt mycelium.

Table 2. Distribution of ${ }^{14} \mathrm{C}$ in components of light-exposed and dark-grown cultures of $P$. isariiforme, fed with ${ }^{14} C$-sucrose* for 4 days

Fraction

Mycelium

Metabolic intermediates (cold

TCA-soluble)

Organic acids $\dagger$

Basic compounds

Glucose

Other neutral compounds

Lipids, phospholipids (EtOH-

soluble + EtOH/ether soluble)

Nucleic acids, polysaccharides

(hot TCA-soluble)

Residual protein and cell walls

Medium

Aspartic+glutamic acid

Malic acid

Citric acid

Remainder

Total (mycelium + medium)

$\overbrace{\text { Component }}^{\left.\text {Light-exposed (d.p.m. } \times 10^{3}\right)}$

$676 \cdot 4(48 \cdot 4 \%)$

I $20 \cdot 6$

$71 \cdot 4$

$295 \cdot 6$

$188 \cdot 8$

$4 \cdot 4$

$6 \cdot 3$

$46 \cdot 1$

$22 \cdot 6$

I36. I $(9 \cdot 7 \%)$

$157 \cdot 3(11 \cdot 2 \%)$

$349 \cdot 0(25 \cdot 0 \%)$

$79 \cdot 4(5 \cdot 7 \%)$

$\overbrace{\text { Component }}^{\text {Dark-grown (d.p.m. } \times 10^{3} \text { ) }}$

$334 \cdot 0(27 \cdot 1 \%)$

$78 \cdot 7$

$47 \cdot 8$

$119 \cdot 3$

$88 \cdot 2$

13.4

$17 \cdot 2$

$317 \cdot 0$

$34 \cdot 4$

$1398 \cdot 2(100 \%)$
$96 \cdot 4(7 \cdot 8 \%)$

$142.5(11.5 \%)$

$280 \cdot 0(22 \cdot 7 \%)$

$382 \cdot 0(30 \cdot 9 \%)$

$1234.9(100 \%)$

* ${ }^{14} \mathrm{C}$-sucrose $4.6 \times 10^{6}$ d.p.m./incubation.

$\uparrow$ Mainly $(90 \%)$ glutamic, aspartic, malic and citric acids.

With regard to the distribution of ${ }^{14} \mathrm{C}$ in the medium, it was evident that in the dark-grown culture a considerable part of the sucrose used was transformed into organic acids, mainly citric acid.

$$
\text { Experiments with }{ }^{14} \mathrm{CO}_{2}
$$

Previously we reported a direct relationship between $\mathrm{CO}_{2}$ assimilation and citric acid synthesis, as $\mathbf{C O}_{2}$ may have an anaplerotic function in oxaloacetate formation via carboxylation of pyruvate or PEP (Graafmans, 1973a,b). Because of the high yield of citric acid in dark-grown cultures it was of interest to study the fixation of $\mathrm{CO}_{2}$. 
Table 3. Radioactivity in medium and mycelium of light-exposed and dark-grown cultures of $P$. isariiforme after ${ }^{14} \mathrm{CO}_{2}{ }^{*}$ pulse-chase labelling

There was a pulse of $60 \mathrm{~s}$ in each experiment, and a chase period of o min and $59 \mathrm{~min}$ in Expts $\mathrm{J}$ and 2, and Expts 3 and 4, respectively. Expts 1 anđ 2 were carried out in duplicate (deviations in parentheses). Radioactivity in citric acid was determined after chromatography of the medium and a TCA extract of the mycelium on Dowex-8 anion resin. Dark-grown culture: 7 days dark. Light-exposed culture: 5 days dark +2 days light.

\begin{tabular}{|c|c|c|c|c|}
\hline & $\begin{array}{c}\text { Expt I } \\
\text { (light-exposed) }\end{array}$ & $\begin{array}{c}\text { Expt } 2 \\
\text { (dark-grown) }\end{array}$ & $\begin{array}{c}\text { Expt } 3 \\
\text { (light-exposed) }\end{array}$ & $\begin{array}{c}\text { Expt } 4 \\
\text { (dark-grown) }\end{array}$ \\
\hline $\begin{array}{l}\text { Mycelium } † \\
\text { Citric acid }\end{array}$ & $366 \cdot 8( \pm 52 \cdot 7)$ & $624 \cdot 2( \pm 38 \cdot I)$ & $\begin{array}{r}243 \cdot 4 \\
89 \cdot 9\end{array}$ & $\begin{array}{l}427 \cdot 9 \\
162 \cdot 5\end{array}$ \\
\hline $\begin{array}{l}\text { Medium } \ddagger \\
\text { Citric acid }\end{array}$ & $1 \cdot 3( \pm 0 \cdot 4)$ & $2 \cdot 7( \pm 0 \cdot 2)$ & $\begin{array}{l}23 \cdot 1 \\
13 \cdot 6\end{array}$ & $\begin{array}{r}107 \cdot 8 \\
93 \cdot 3\end{array}$ \\
\hline $\begin{array}{l}\text { Mycelium + medium } \\
\text { Citric acid }\end{array}$ & $368 \cdot 1( \pm 53 \cdot 1)$ & $626 \cdot 9( \pm 38 \cdot 3)$ & $\begin{array}{l}266 \cdot 5 \\
103 \cdot 5\end{array}$ & $\begin{array}{l}535 \cdot 7 \\
255 \cdot 8\end{array}$ \\
\hline
\end{tabular}

A pulse of ${ }^{14} \mathrm{CO}_{2}$ was given for a short period of time to prevent dilution of the label $\left(\mathrm{CO}_{2}\right.$ production by the mycelium was less than $2 \%$ of the ${ }^{14} \mathrm{CO}_{2}$ administered during the time of incubation). As all the assimilated ${ }^{14} \mathrm{CO}_{2}$ was not permanently fixed in cellular components, but partly set free again by decarboxylation, radioactivity should also be measured after a chase period (Graafmans, 1973a).

From the results in Table 3, it appeared that more ${ }^{14} \mathrm{CO}_{2}$ was assimilated by the darkgrown mycelium. After a chase period of $59 \mathrm{~min}$, the content of labelled components in this culture type remained higher than in the parallel light-exposed culture. This was also true for citric acid.

\section{DISCUSSION}

There appears to be an important shift in metabolism when Penicillium isariiforme is exposed to light. Light stimulated the synthesis of cell components, resulting in a $90 \%$ increase in dry weight after 4 days of illumination compared with the dark control. No significant differences in sucrose uptake were observed between the two treatments, but in the illuminated culture the accumulation of citric acid decreased considerably.

Differences in dry weight between mycelia cultured in darkness or in the light were also demonstrated by Piskorz (1972), although the excretion of organic acids in the medium was not taken into account. Piskorz observed that the consumption of glucose was equal in both culture types and suggested that the increased mycelial dry weight in the light might be due to a stimulated carboxylation.

The results presented in this paper, however, suggest that the conversion of sucrose into cell components other than citric acid might partly explain the increase in dry weight upon exposure to light. Moreover, with regard to ${ }^{14} \mathrm{CO}_{2}$ fixation the present results seem to be at variance with those of Piskorz (1972), as we observed a stimulated assimilation of this compound in dark-grown mycelium. Previously, we reported the anaplerotic role of carbon dioxide in citric acid synthesis in this fungus (Graafmans, $1973 a, b$ ). The stimulated assimila- 
tion of carbon dioxide in dark-grown cultures is in agreement with the increased accumulation of citric acid

Goldstein \& Cantino (1962) observed that in synchronized cultures of Blastocladiella emersonii the dry weight, soluble protein and especially the soluble polysaccharide increased more rapidly in the light. They suggested that light inhibited the pathway for glucose degradation, shunting the metabolism towards the manufacture of polysaccharides. It is therefore of importance to study the influence of light on carbohydrate metabolism and on the flow of carbon to the citric acid cycle in Penicillium isariiforme.

I am grateful to Professor Dr D. Stegwee, Dr G. Bennink and Dr H. van den Ende for helpful discussions and for reading the manuscript.

\section{REFERENCES}

Bennink, G. J. H. (1972). Photomorphogenesis in Penicillium isariiforme. II. The action spectrum for lightinduced formation of Coremia. Acta botanica neerlandica 21, 535-538.

BURNETT, J. H. (1968). Fundamentals of Mycology. London: Edward Arnold.

Carlne, M. J. (1970). The photoresponses of fungi. In Photobiology of Microorganisms, pp. 309-344. Edited by P. Halldal. London: Wiley-Interscience.

Carlile, M. J., Dickens, J. S. W., Mordue, E. M. \& Schipper, M. A. A. (I962). The development of Coremia. II. Penicillium isariiforme. Transactions of the British Mycological Society 45, 457-461.

Goldstein, A. \& CANTINo, E.C. (1962). Light stimulated polysaccharide and protein synthesis by synchronized, single generations of Blastocladiella emersonii. Journal of General Microbiology 28, 689-699.

GraAfmans, W. D. J. (1973a). The influence of carbon dioxide on morphogenesis in Penicillium isariiforme. Archiv für Mikrobiologie 91, 67-76.

GraAfmans, W. D. J. (1973 $b$ ). The influence of carbon dioxide on sporulation and citric acid synthesis in dark-grown Penicillium isariiforme. Acta botanica neerlandica 22, 543-545.

PisKorz, B. (1967). Investigations on the formation of Coremia. I. Action of light on the formation of Coremia in Penicillium isariaeforme. Acta Societatis botanicorum Poloniae 36, I23-131.

Piskorz, B. (1972). Comparative investigations on the development of fungi from the section of Penicillium clavigerum. III. Acta Societatis botanicorum Poloniae 4I, 34I-355.

Roberts, R. B., Cowie, D. B., Abelson, P. H., Bolton, E. T. \& BrITTEN, R. J. (1955). Studies of Biosynthesis in Escherichia coli. Publication 607, pp. I3-30. Washington, D.C.: Carnegie Institution.

SMith, J. E. \& Galbraith, J. C. (1971). Biochemical and physiological aspects of differentiation in the fungi. In Advances in Microbial Physiology, vol. 5, pp. 45-134. Edited by A. H. Rose and J. F. Wilkinson. New York and London: Academic Press.

Wessels, J. G. H., Kreger, D. R., Marchant, R., Regensburg, B. A. \& de Vries, O. M. H. (1972). Chemical and morphological characterization of the hyphal wall surface of the basidiomycete Schizophyllum commune. Biochimica et biophysica acta 273, 346-358. 